\title{
Energetics and reactivity of small beryllium deuterides
}

\author{
Ivan Sukuba $^{1,2}$ (D) $\cdot$ Alexander Kaiser ${ }^{1} \cdot$ Stefan E. Huber $^{1} \cdot$ Jan Urban $^{2} \cdot$ Michael Probst $^{1}$
}

Received: 15 November 2016 / Accepted: 4 May 2017 / Published online: 16 June 2017

(C) The Author(s) 2017. This article is an open access publication

\begin{abstract}
Enthalpies and free energies of reaction for small neutral and charged beryllium deuterides $\mathrm{BeD}$, $\mathrm{BeD}_{2}$, and $\mathrm{BeD}_{3}$ that have been calculated are reported for a temperature range of $0 \mathrm{~K}$ to $1000 \mathrm{~K}$. We discuss probable dissociation channels and possible ways of producing $\mathrm{BeD}$ by localizing the relevant transition states and by calculating corresponding rate constants. BeD and $\mathrm{BeD}^{+}$are found to be the most stable ones among the considered compounds. $\mathrm{BeD}_{2}$ and $\mathrm{BeD}_{2}^{+}$are more likely to decompose into $\mathrm{Be}^{0,+}+\mathrm{D}_{2}$ than into $\mathrm{BeD}^{0,+}+\mathrm{D}$. The metastable $\mathrm{BeD}_{3}$ and $\mathrm{BeD}_{3}^{+}$predominantly decompose into $\mathrm{BeD}^{0,+}+\mathrm{D}_{2}$. In light of our results on the reaction energetics, we can interpret the pathways for production of $\mathrm{BeD}$ via $\mathrm{BeD}_{2}$ and $\mathrm{BeD}_{3}$ intermediates observed in molecular dynamics simulations.
\end{abstract}

Keywords Beryllium deuterides · Dissociation · ITER · Reactivity · Quantum-chemical calculations · Molecular dynamics

This paper belongs to Topical Collection 7th Conference on Modeling \& Design of Molecular Materials in Trzebnica (MDMM 2016)

Ivan Sukuba

ivan.sukuba@uibk.ac.at

1 Institute of Ion Physics and Applied Physics, University of Innsbruck, Technikerstraße 25, A-6020 Innsbruck, Austria

2 Department of Nuclear Physics and Biophysics, Faculty of Mathematics, Physics and Informatics, Comenius University, SK-84248 Bratislava, Slovakia

\section{Introduction}

The development of new technologies for controlled fusion caused beryllium compounds, especially hydrides that can be created by $\mathrm{D} / \mathrm{T}$ bombardment from plasma, to become one focus of materials research. In the ITER reactor, beryllium is planned to be the first-wall material, and hence it will be directly exposed to particles, predominantly deuterons, that escape the confinement as is already observed in the JET tokamak with ITER-like walls $[1,2]$. For many years, plasma-wall interactions (PWI) have been extensively studied experimentally as well as theoretically. The main source of experimental data concerning beryllium-deuterium interactions are linear devices like PISCES-B [3, 4] or tokamaks [5-7]. However, the underlying processes like sputtering, transport and deposition are hard to reproduce and quantify experimentally. Modeling and theoretical approaches to obtain data for codes like Wall-DYN [8], ERO [9] or SDTrimSP [10, 11] are therefore developed to get insight into such processes. Theoretical studies of plasma wall interactions involve the description of the interaction of surfaces with the fusion plasma [12], the characterization of elementary processes [13] as well as the validation of experimental results [14, 15]. Experimental results of plasma-surface interactions confirm the complexity of the whole process. Concerning beryllium experiments, there is evidence of the formation of $\mathrm{BeD}$ molecules and of a linear drop of the $\mathrm{BeD}: \mathrm{Be}$ ratio with increasing temperature in the temperature range of 500-700 K while no larger molecules like $\mathrm{BeD}_{2}$ or $\mathrm{BeD}_{3}$ were observed [7]. In contrast, molecular dynamics (MD) simulations employing analytical bond-order potentials (ABOP) [16, 17], as well as multiscale modeling extrapolated from them [18] predict $\mathrm{BeD}_{2}$ and $\mathrm{BeD}_{3}$ as the main eroded species for the same 
temperature range [19]. Since at lower temperatures $(<500 \mathrm{~K})$ MD simulations were in agreement with experiment, a more complete description of the possible fragmentation processes is needed from both the energetic and kinetic points of view. Dissociation and reactivity of beryllium hydrides and their isotopes were briefly discussed by Safi et al. [19] and Virot et al. [20] on the basis of standard thermodynamic data and possible reaction channels were given for the dissociation of $\mathrm{BeD}_{2}$ and $\mathrm{BeD}_{3}$ at various temperatures. The dissociation and ionization rates for primary reactions of $\mathrm{BeD}$ due to electron collisions were reported by Björkas et al. [18]. In the present work, we employ quantum chemical methods including comparisons between various levels of theory and we study the reaction kinetics to determine the reactivity of different channels. Highly accurate data have been published before on the beryllium hydrogen systems: $\mathrm{BeH}$ as well as $\mathrm{BeH}_{2}$ have received a significant amount of interest as a test system for quantum chemical methods including non-standard ones [21-29]. The multi-reference averaged coupled-pair functional method (MR ACPF) [21] was used to calculate the accurate ground state potential energy functions, vibration-rotation energy levels for $\mathrm{BeH}, \mathrm{BeD}$, and $\mathrm{BeT}$ and their ions, which agree excellently with spectroscopic experimental data, i.e., the equilibrium bond length $\mathrm{R}_{\mathrm{e}}=1.341 \AA[22,23]$. Non-BornOppenheimer variational calculations employing explicitly correlated Gaussian basis functions were performed in order to determine the ionization energy of $\mathrm{BeH}$ and the dissociation energies of $\mathrm{BeH}$ and $\mathrm{BeH}^{+}$[24]. Penotti's [26] non-orthogonal single and multi-configurational calculations with a highly optimized even-tempered STO basis set yielded a value of $\mathrm{R}_{\mathrm{e}}=1.329 \AA$ for the $\mathrm{D}_{\infty \mathrm{h}}$ geometry of the $\mathrm{BeH}_{2}$ molecule. A value of $2053.0 \mathrm{~cm}^{-1}$ was obtained for the harmonic symmetric-stretch frequency. Very precise results for the $\mathrm{BeH}$ system also included non-adiabatic effects and extrapolation of the basis set up to the spdfgh level as well as extrapolation of correlation effects to the full configuration interaction (FCI) limit [28]. An equilibrium distance of $\mathrm{R}_{\mathrm{e}}=1.341 \AA$ and a ground state frequency of $\omega_{\mathrm{e}}=2062.1 \mathrm{~cm}^{-1}$ were reported. Hinze et al. [29] published potential energy surfaces (PESs) for $\mathrm{BeH}_{2}$ and $\mathrm{BeH}_{2}^{+}$obtained with the multireference configuration interaction method (MRCI) and documented the insertion reaction of $\mathrm{Be}$ into $\mathrm{H}_{2}$. Koput and Peterson [30] obtained vibrational and rotational energy levels of beryllium dihydride and of its isotopes from an accurate potential energy surface using CCSD (T) and extrapolation to the full basis set limit. The IR emission spectra for $\mathrm{BeH}$ and $\mathrm{BeH}_{2}$ were measured by Bernath and coworkers [31-34]. They obtained $\mathrm{R}_{\mathrm{e}}=1.342 \AA$, $\omega_{\mathrm{e}}=2061.4 \mathrm{~cm}^{-1}$ for $\mathrm{BeH}$, and $\mathrm{R}_{\mathrm{e}}=1.326 \AA$, $\omega_{\mathrm{e}}=2255.2 \mathrm{~cm}^{-1}$ for the asymmetric stretch for $\mathrm{BeH}_{2}$.
Reaction enthalpies for the dissociation channels of the $\mathrm{BeD}_{3}$ molecule were calculated in ref. [19] and the thermodynamic stability of neutral and anionic $\mathrm{BeH}_{3}$ was analyzed in ref. [35]. The knowledge of the whole reaction network is necessary for understanding the chemical behavior of the $\mathrm{Be} / \mathrm{H}$ system. This work aims to describe the fragmentation and reactivity of small beryllium deuterides in the temperature range $0-1000 \mathrm{~K}$ and is based on quantum-chemistry calculations and transition state theory. We report a stability analysis, thermodynamic data of neutral and charged $\mathrm{BeD}_{1-3}$ molecules, the standard enthalpies and free energies of reaction for their possible dissociation channels, and their corresponding dissociation energies. Calculated transition states and activation energies can be used to estimate reaction rate constants. Furthermore, reaction schemes for the production of BeD from beryllium surfaces exposed to D irradiation as extracted from MD simulations are discussed.

\section{Computational methods}

\section{Quantum-chemical calculations}

The optimized structures and vibrational frequencies of the beryllium hydrides were obtained by the Gaussian- 4 (G4) [36] method and by density functional theory (DFT). We compared different DFT functionals: the often used hybrid functional B3LYP-D [37, 38], the B97D functional and the meta-GGA M06 functional [39]. The first two functionals contain Grimme's GD3 empirical dispersion parameters [40]. We also employed the double hybrid B2PLYPD [41, 42] functional which includes dispersion and density corrections by second-order Møller-Plesset perturbation theory (MP2) [43]. Furthermore, we optimized the predicted structures by coupled cluster calculations with single and double substitutions and noniteratively included triple excitations $(\operatorname{CCSD}(\mathrm{T}))$ [44] with all electrons correlated. All calculations were performed with Dunning's correlation consistent core-valence quadruple zeta (aug-cc-pCVQZ) basis set [45], the sole exception being the pre-defined G4 method, and employed the GAUSSIAN 09 software package [46]. Different scaling factors are recommended for some of the methods used throughout this study [47]. However, we report unscaled frequencies here with the intention to introduce as little empiricism as possible.

\section{Thermodynamics}

In order to qualitatively examine the reactivity of small beryllium deuterides (hydrides), we first calculated the standard enthalpies and the standard free energies of the 
Table 1 Enthalpies of formation of elements in the gas state and thermal corrections to these enthalpies. Values are in $\mathrm{kJ} \mathrm{mol}^{-1}$ rounded to two decimal points. Experimental and calculated $\mathrm{H}_{\text {corr }}^{0 \rightarrow 298.15}$ for hydrogen atoms were obtained from $\mathrm{H}_{2}\left(\mathrm{D}_{2}\right)$ values with the NISTJANAF database [49]. The reference state for Be is a hcp crystal structure up to $1560 \mathrm{~K}$, the calculated value refers to the gas state

\begin{tabular}{lllllrr}
\hline & $\mathbf{B e}$ & $\mathbf{B e}^{+}$ & $\mathbf{H}$ & $\mathbf{H}^{+}$ & $\mathbf{D}^{+}$ & 1492.29 \\
\hline$\Delta_{\boldsymbol{f}} \boldsymbol{H}_{0 \boldsymbol{K}^{\circ}}^{\circ}$ & 319.74 & 1219.23 & 216.04 & 1488.36 & 219.77 & 4.33 \\
$\boldsymbol{H}_{\text {corr }}^{0 \rightarrow 298.15}$ exp. & 1.93 & 6.20 & 4.23 & 4.29 & 4.29 & 4.34 \\
$\boldsymbol{H}_{\text {corr }}^{0 \rightarrow 298.15}$ calc. & 6.20 & 6.20 & 4.34 & 4.34 & 4.34 \\
\hline
\end{tabular}

reactants and products of the dissociation channels (Eq. 1). The standard enthalpies (the free energies) of reaction were calculated as a difference of the sum of electronic energy $\varepsilon_{0}$, zero-point energy $\epsilon_{\mathrm{ZPE}}$ and thermally corrected enthalpies (free energies) of products and reactants [48]:

$$
\begin{aligned}
\Delta_{r} H^{\circ}(\mathrm{T})=\sum_{\text {products }}\left(\varepsilon_{0}+\epsilon_{Z P E}+H_{\text {corr }}(\mathrm{T})\right)-\sum_{\text {reactants }} \\
\left(\varepsilon_{0}+\epsilon_{Z P E}+H_{\mathrm{corr}}(\mathrm{T})\right)
\end{aligned}
$$

and similarly for $\Delta_{\mathrm{r}} \mathrm{G}^{\circ}(\mathrm{T})$. Only calculated values were used to obtain $\Delta_{\mathrm{r}} \mathrm{H}^{\circ}$ and $\Delta_{\mathrm{r}} \mathrm{G}^{\circ}$. Subsequently, equilibrium constants, $\mathrm{K}_{\mathrm{EQ}}$, were obtained from the standard free energies of reactions:

$\mathrm{K}_{\mathrm{EQ}}(T)=e^{\frac{-\Delta_{r} G^{\circ}(T)}{R T}}$

The standard enthalpies of formation of molecules at $298.15 \mathrm{~K}, \Delta_{f} \mathrm{H}^{\circ}(\mathrm{M})$, were calculated using experimental enthalpies of formation for elements, $\Delta_{\mathrm{f}} \mathrm{H}_{0 K}(\mathrm{X})$ and their corresponding thermal corrections, $\mathrm{H}_{\text {corr }}^{0 \rightarrow 298.15}$, (see
Table 1) and the procedure suggested by McQuarrie [48]:

$$
\begin{aligned}
& \Delta_{f} \mathrm{H}^{\circ}(\mathrm{M})= \Delta_{f} \mathrm{H}_{0 K}^{\circ}(\mathrm{M}) \\
&+H_{\text {corr }}^{0 \rightarrow 298.15}(\mathrm{M})-\sum_{\text {atoms }} x H_{\text {corr }}^{0 \rightarrow 298.15}(\mathrm{X}) \\
& \Delta_{f} \mathrm{H}^{\circ}{ }_{0 K}(\mathrm{M})= \sum_{\text {atoms }} x \Delta_{f} \mathrm{H}_{0 K^{\circ}}^{\circ}(\mathrm{X})-D_{0}(M) \\
& D_{0}(M)=\left(\sum_{\text {atoms }} x \epsilon_{0}(X)-\epsilon_{0}(M)-\epsilon_{Z P E}(M)\right)
\end{aligned}
$$

where $D_{0}$ is the dissociation energy which is equal to the atomization energy for a number of $\mathrm{x}$ atoms of the type $\mathrm{X}$ in molecule M. We compared the selected methods by comparing thermodynamic data of the $\mathrm{BeH}$ and the $\mathrm{BeH}_{2}$ molecules with experimental data from the NIST-JANAF database [49]. The results are shown in Table 2. All methods predict values of $\Delta_{\mathrm{f}} \mathrm{H}^{\circ}(\mathrm{BeH})$ rather close to the experimental value of $321 \pm$ $30 \mathrm{~kJ} \mathrm{~mol}^{-1}(=3.3 \pm 0.3 \mathrm{eV})$ [49], with $\operatorname{CCSD}(\mathrm{T})$ differing the most by $\sim 19 \mathrm{~kJ} \mathrm{~mol}^{-1}(0.2 \mathrm{eV}) . \Delta_{\mathrm{f}} \mathrm{H}^{\circ}\left(\mathrm{BeH}_{2}\right)$ is significantly overestimated compared to the experimental value of
Table 2 Comparison of calculated thermodynamic properties as obtained by various methods for $\mathrm{BeH}, \mathrm{BeH}_{2}$, and $\mathrm{H}_{2}\left(\mathrm{D}_{2}\right)$ molecules to known experimental values. $\Delta_{f} H^{\circ}$ is in $\mathrm{kJ} \mathrm{mol}^{-1}, \mathrm{R}_{\mathrm{e}}$ in $\AA$, and $\omega_{\mathrm{e}}$ in $\mathrm{cm}^{-1}$. The enthalpy of formation for $\mathrm{BeH}$ and its estimation for $\mathrm{BeH}_{2}$ are taken

\begin{tabular}{|c|c|c|c|c|c|c|c|c|c|c|}
\hline \multirow[t]{2}{*}{ Method } & \multicolumn{3}{|c|}{ ВeH } & \multicolumn{4}{|l|}{$\mathrm{BeH}_{2}$} & \multicolumn{2}{|l|}{$\mathbf{H}_{2}$} & \multirow{2}{*}{$\frac{\mathbf{D}_{\mathbf{2}}}{\omega_{e}}$} \\
\hline & $\Delta_{\boldsymbol{f}} \boldsymbol{H}^{\circ}$ & $\boldsymbol{R}_{e}$ & $\omega_{e}$ & $\Delta_{f} \boldsymbol{H}^{\circ}$ & $\boldsymbol{R}_{e}$ & $\omega_{e}^{a}$ & $\omega_{e}^{b}$ & $\boldsymbol{R}_{\boldsymbol{e}}$ & $\omega_{e}$ & \\
\hline B3LYP-D & 307.86 & 1.340 & 2062.4 & 133.7 & 1.324 & 2263.5 & 724.8 & 0.742 & 4415.2 & 3123.2 \\
\hline B97D & 328.60 & 1.367 & 1936.8 & 140.98 & 1.337 & 2201.8 & 706.0 & 0.744 & 4373.5 & 3093.7 \\
\hline B2PLYPD & 316.65 & 1.338 & 2084.9 & 144.90 & 1.323 & 2278.4 & 726.8 & 0.740 & 4461.2 & 3155.8 \\
\hline M06 & 313.34 & 1.341 & 2089.0 & 128.77 & 1.326 & 2264.6 & 705.2 & 0.744 & 4423.8 & 3129.3 \\
\hline G4 & 331.52 & 1.344 & 2064.5 & 158.93 & 1.327 & 2275.6 & 746.3 & 0.743 & 4465.7 & 3159.0 \\
\hline $\operatorname{CCSD}(T)$ & 340.23 & 1.342 & 2062.4 & 168.31 & 1.327 & 2257.2 & 717.1 & 0.742 & 4401.1 & 3113.2 \\
\hline Exp. & $321 \pm 30$ & 1.342 & 2061.4 & 125.52 & 1.326 & 2255.2 & 706.3 & 0.741 & 4401.2 & 3115.5 \\
\hline
\end{tabular}
from ref. [50]. Experimental values for the hydrogen molecule are taken from the NIST-JANAF thermochemical Tables [49]. Spectroscopic values for $\mathrm{BeH}$ and $\mathrm{BeH}_{2}$ are retrieved from ref. [32, 33]. $\omega_{e}^{a}$ for $\mathrm{BeH}_{2}$ corresponds to the asymmetric stretching vibration and $\omega_{e}^{b}$ to the bending vibration 


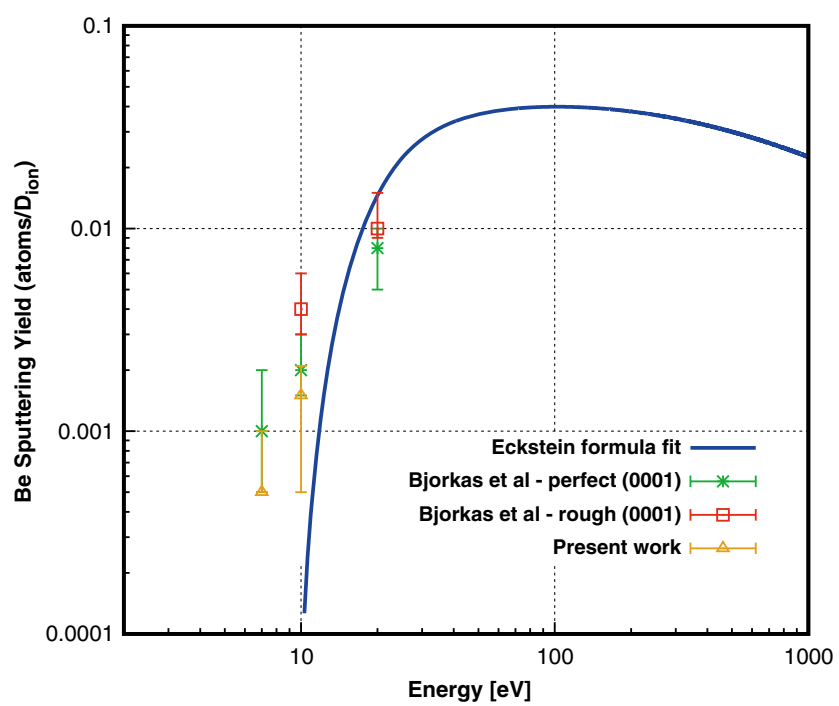

Fig. 1 Sputtering yields obtained from MD simulations of D irradiated Be surfaces compared with literature data [15]

$\sim 125.52 \mathrm{~kJ} \mathrm{~mol}^{-1}(1.3 \mathrm{eV})$ which is based on an empirical method [49, 50]. For $\mathrm{BeH}_{2}$, the DFT functionals overall give values closer to the experimental value than the higher order methods, which differ by $\sim 33-43 \mathrm{~kJ} \mathrm{~mol}^{-1}(0.3-0.5 \mathrm{eV})$. The M06 functional predicts enthalpies of formation closest to the reference values. B3LYP-D and CCSD(T) harmonic frequencies are closest to the experimental data. The harmonic frequency for BeD obtained with B3LYP-D and $\operatorname{CCSD}(\mathrm{T})$ methods, $1530.4 \mathrm{~cm}^{-1}$, agrees well with the experimental value of $1529.5 \mathrm{~cm}^{-1}$ [32].

Eventually, to obtain the total change of the free energy of reaction, a term dependent on initial concentrations or more generally on instantaneous activities $a_{j}^{v_{j}}$ of products and $a_{i}^{v_{i}}$ of reactants, referred to as reaction quotient, $Q_{r}$, has to be added [48]:

$$
\begin{aligned}
& \Delta_{r} \mathrm{G}(\mathrm{T})=\Delta_{r} G^{\circ}(T)+R T \ln Q_{r}=\mathrm{RT} \ln \frac{Q_{r}}{K_{E Q}} \\
& Q_{r}=\frac{\prod_{j} a_{j}^{v_{j}}(t)}{\prod_{i} a_{i}^{v_{i}}(t)}
\end{aligned}
$$

Table 3 Bond lengths and angles of the beryllium hydrides. The lengths are given in $\AA$, angles in degrees. For the meaning of $R_{1}$ and $R_{2}$ see Fig. 3 . The

\begin{tabular}{|c|c|c|c|c|c|c|c|c|c|c|c|}
\hline & \multirow{2}{*}{$\begin{array}{l}\mathbf{B e H}^{+} \\
R_{e}\end{array}$} & \multirow{2}{*}{$\begin{array}{l}\mathbf{B e H}^{-} \\
R_{e}\end{array}$} & \multicolumn{2}{|c|}{$\mathrm{BeH}_{2}^{+} \mathbf{I}$} & \multicolumn{2}{|c|}{$\mathrm{BeH}_{2}^{+} \mathrm{II}$} & \multicolumn{2}{|l|}{$\mathrm{BeH}_{3}$} & \multicolumn{2}{|c|}{$\mathrm{BeH}_{3}^{+}$} & \multirow{2}{*}{$\begin{array}{l}\mathbf{B e H}_{3}{ }^{-} \\
R_{I}\end{array}$} \\
\hline & & & $B e-H$ & $H-B e-H$ & $B e-H$ & $H-B e-H$ & $R_{1}$ & $R_{2}$ & $R_{I}$ & $R_{2}$ & \\
\hline B3LYP-D & 1.313 & 1.408 & 1.411 & 93.3 & 1.877 & 23.6 & 1.322 & 1.417 & 1.299 & 1.663 & 1.415 \\
\hline B97D & 1.324 & 1.424 & 1.427 & 99.2 & 1.921 & 23.1 & 1.333 & 1.432 & 1.311 & 1.706 & 1.430 \\
\hline B2PLYPD & 1.310 & 1.407 & 1.403 & 86.5 & 1.403 & 86.5 & 1.321 & 1.415 & 1.297 & 1.655 & 1.413 \\
\hline M06 & 1.307 & 1.397 & 1.404 & 89.5 & 1.883 & 23.5 & 1.322 & 1.421 & 1.298 & 1.693 & 1.415 \\
\hline G4 & 1.320 & 1.477 & 1.416 & 94.6 & 1.855 & 23.8 & 1.324 & 1.418 & 1.305 & 1.657 & 1.408 \\
\hline $\operatorname{CCSD}(\mathrm{T})$ & 1.311 & 1.412 & 1.399 & 80.1 & 1.817 & 24.3 & 1.324 & 1.416 & 1.299 & 1.651 & 1.418 \\
\hline
\end{tabular}
data for $\mathrm{BeH}$ and $\mathrm{BeH}_{2}$ are given in Table 2
The ratio $Q_{r} / K_{E Q}$ determines the direction of reaction: if $Q_{r}>K_{E Q}$, the reaction favors the reactants; if $Q_{r}<K_{E Q}$, the products are preferable. The reaction is in equilibrium for $Q_{r}$ $=K_{E Q}$. The reaction quotients were not calculated nor otherwise included for studied dissociation channels in this work.

\section{Localizing transition states and calculating rate constant}

Approximate transition states geometries were at first guessed instead of using computational methods such as QST2 [51]. These structures were then optimized using the B3LYP-D functional. It was checked by vibrational frequency analysis modes corresponding to the reaction path. In addition, IRC calculations were performed to ensure that the obtained transition states connect the local minima on the PES which refer to reactants and products for the considered reactions. Subsequently, obtained structures were optimized by the $\operatorname{CCSD}(\mathrm{T})$ method. The rate constants were determined only for dissociation channels with $\log \left(\mathrm{K}_{\mathrm{EQ}}\right)>-5$ for any point in the temperature range from 0 to $1000 \mathrm{~K}$ because those are the reactions most affecting plasma-wall interactions. In case of reactions with $\log \left(\mathrm{K}_{\mathrm{EQ}}\right)<-5$ nearly only reactants will appear in the equilibrium mixture [48]. We used transition state theory (TST) to estimate the reaction rate constants for temperature $\mathrm{T}$ by employing the Eyring-Polanyi Eq. [52]:

$k(T)=\frac{k_{B} T}{h} \frac{1}{c^{n}} e^{\frac{\Delta G^{\ddagger}(T)}{R T}}$

$\ln \frac{k(T)}{T}=\frac{-\Delta H^{\ddagger}}{R} \frac{1}{T}+\ln \frac{k_{B}}{h}+\frac{\Delta S^{\ddagger}}{R}$

where $\mathrm{k}_{\mathrm{B}}$ is the Boltzmann constant, $\mathrm{R}$ the gas constant, $\mathrm{h}$ the Planck constant, $\mathrm{c}$ the concentration, $\mathrm{n}$ the order of reaction, and $\Delta \mathrm{G}^{\ddagger}$ is the free energy of activation. We set $\mathrm{c}$ to 1 for results in the present work. The linear form of this equation (Eq. 6.b), where $\Delta H^{*}$ and $\Delta S^{\star}$ are the enthalpy and entropy of activation, was used to present the calculated rate constants. From the rate constants, we are able to determine the reaction schemes for that a transition state has only one imaginary frequency, with 
Table 4 Dissociation energy $\mathrm{D}_{0}$ and enthalpy of formation for the neutral beryllium deuterides. The electron affinity $\mathrm{EA}$ of $\mathrm{BeH}$ and $\mathrm{BeH} 3$ are also listed. All values are in $\mathrm{kJ} \mathrm{mol}^{-1}$

\begin{tabular}{|c|c|c|c|c|c|c|c|c|}
\hline \multirow[t]{2}{*}{ Method } & \multicolumn{2}{|l|}{ BeD } & \multicolumn{2}{|l|}{$\mathrm{BeD}_{2}$} & \multicolumn{2}{|l|}{$\mathrm{BeD}_{3}$} & \multirow{2}{*}{$\frac{\mathrm{BeH}=>\mathrm{BeH}^{-}}{\text {EA }}$} & \multirow{2}{*}{$\frac{\mathrm{BeH}_{3}=>\mathrm{BeH}_{3}{ }^{-}}{\text {EA }}$} \\
\hline & $\mathbf{D}_{0}$ & $\Delta_{f} \boldsymbol{H}^{\circ}$ & $\mathbf{D}_{0}$ & $\Delta_{f} H^{\circ}$ & $D_{0}$ & $\Delta_{f} H^{\circ}$ & & \\
\hline B3LYP-D & 233.6 & 308.4 & 625.6 & 132.8 & 680.5 & 295.8 & 50.9 & 275.1 \\
\hline B97D & 212.7 & 329.3 & 618.2 & 140.3 & 668.4 & 307.9 & 70.9 & 273.1 \\
\hline B2PLYPD & 207.4 & 334.6 & 597.0 & 161.4 & 633.6 & 342.6 & 39.4 & 267.8 \\
\hline M06 & 224.9 & 317.1 & 614.5 & 143.9 & 658.4 & 317.7 & 44.6 & 273.1 \\
\hline G4 & 228.2 & 313.8 & 630.6 & 127.9 & 661.4 & 314.9 & 63.0 & 286.2 \\
\hline $\operatorname{CCSD}(T)$ & 198.1 & 340.7 & 591.0 & 167.4 & 628.1 & 348.1 & 51.8 & 278.0 \\
\hline
\end{tabular}

unmixed reactants and products in their standard states at the pressure of 1 atm and thus can predict the feasibility of the studied reactions based on the data from computational electronic structure methods and the rules of chemical kinetics.

\section{Molecular dynamics simulations}

We studied the sputtering of BeD by low energy D irradiation from pure Be surfaces by means of molecular dynamics (MD) simulations using the same procedure as in ref. [15]. The $\mathrm{D}^{+}$ bombardment was simulated with the DL_POLY 3.9 software [53] which was extended to include ABOP potentials [54]. The details and parameters of the $\mathrm{Be}-\mathrm{H}$ potentials are given in ref. [17]. The hexagonal closed packed Be surface (0001) with 3718 atoms $(30 \times 30 \times 40 \AA)$ was equilibrated by slowly heating the samples to $300 \mathrm{~K}$ at a rate of $50 \mathrm{~K} / \mathrm{ps}$. Subsequently, 1000 cumulative D impacts with 7, 10, and $20 \mathrm{eV}$ were performed from a distance of $5 \AA$ perpendicular to the center of the surface. A single impact lasted 7 ps and was divided into two parts: the first 3 ps consist of the impact itself followed by 4 ps of relaxation of the cell to remove extra energy from the system. Each step lasted $0.5 \mathrm{fs}$. The surface was randomly shifted in $\mathrm{x}-$ and $\mathrm{y}-$ directions after each impact. We compared the sputtering yields with other work (see Fig. 1) and extracted data about single sputtering events to look closer at the mechanisms.

\section{Results and discussion}

\section{Stability analysis}

We obtained optimized geometries of neutral and charged $\mathrm{BeH}$, $\mathrm{BeH}_{2}$, and $\mathrm{BeH}_{3}$ molecules from the various functionals, the $\mathrm{G} 4$, and $\mathrm{CCSD}(\mathrm{T})$ methods. Concerning $\mathrm{BeH}_{2}$ the optimized structures all have negative electron affinities with an absolute value of $5-32 \mathrm{~kJ} \mathrm{~mol}^{-1}(0.1-0.3 \mathrm{eV})$, i.e., an energy is required to attach an electron. They are thus thermodynamically unstable and were removed from further analysis. $\mathrm{Be}, \mathrm{H}$, and $\mathrm{H}_{2}$ are also included in this analysis. The structural properties of $\mathrm{H}_{2}, \mathrm{BeH}$, and $\mathrm{BeH}_{2}$ are given in Table 2, the ones for the remaining molecules are summarized in Table 3. Dissociation energies and enthalpies of formation for neutral and positive ions of beryllium deuterides are given in Tables 4 and 5, respectively.

The bond lengths for $\mathrm{BeH}$ range from 1.338 to $1.367 \AA$, with $\operatorname{CCSD}(\mathrm{T})$ and M06 being closest to the experimental value of $1.342 \AA$ [32]. The bond length of the respective cation is shorter by $0.03 \pm 0.01 \AA$ on average, whereas the bond length of the respective anion is longer by $0.08 \pm 0.03 \AA$. The Be-H bond lengths of neutral $\mathrm{BeH}_{2}$ range from 1.323 to $1.337 \AA$. Again, the CCSD(T) and M06 values agree excellently with the experimental bond length of $1.326 \AA$ [33]. All methods predict two bent structures for $\mathrm{BeH}_{2}^{+}$, with $\mathrm{H}-\mathrm{Be}-\mathrm{H}$ angles of $\sim 90^{\circ}$ (I) and $\sim 24^{\circ}$ (II), and a multiple saddle point
Table 5 Dissociation energy $\mathrm{D}_{0}$ and enthalpy of formation for the cationic beryllium deuterides. All values are in $\mathrm{kJ} \mathrm{mol}^{-1}$

\begin{tabular}{|c|c|c|c|c|c|c|c|c|}
\hline \multirow[t]{2}{*}{ Method } & \multicolumn{2}{|l|}{$\mathbf{B e D}^{+}$} & \multicolumn{2}{|c|}{$\mathrm{BeD}_{2}{ }^{+} \mathrm{I}$} & \multicolumn{2}{|c|}{$\mathrm{BeD}_{2}{ }^{+} \mathrm{II}$} & \multicolumn{2}{|l|}{$\mathrm{BeD}_{3}{ }^{+}$} \\
\hline & $D_{0}$ & $\Delta_{\boldsymbol{f}} \boldsymbol{H}^{\circ}$ & $\mathbf{D}_{0}$ & $\Delta_{\boldsymbol{f}} \boldsymbol{H}^{\circ}$ & $D_{0}$ & $\Delta_{\boldsymbol{f}} \boldsymbol{H}^{\circ}$ & $\mathbf{D}_{0}$ & $\Delta_{\boldsymbol{f}} \boldsymbol{H}^{\circ}$ \\
\hline B3LYP-D & 292.7 & 395.7 & 395.7 & 1148.8 & 482.6 & 1177.2 & 831.8 & 1045.1 \\
\hline B97D & 316.8 & 414.3 & 414.3 & 1124.7 & 483.5 & 1776.4 & 853.6 & 1023.5 \\
\hline B2PLYPD & 301.3 & 361.5 & 361.5 & 1140.2 & 472.8 & 1189.7 & 835.8 & 1041.0 \\
\hline M06 & 289.6 & 363.3 & 363.3 & 1151.9 & 465.8 & 1195.0 & 822.2 & 1054.8 \\
\hline G4 & 306.6 & 379.5 & 379.5 & 1134.9 & 477.1 & 1182.4 & 832.8 & 1044.3 \\
\hline $\operatorname{CCSD}(\mathrm{T})$ & 296.8 & 370.5 & 370.5 & 1144.7 & 471.1 & 1188.1 & 828.7 & 1048.2 \\
\hline
\end{tabular}


a)

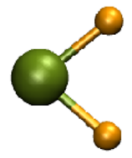

b)

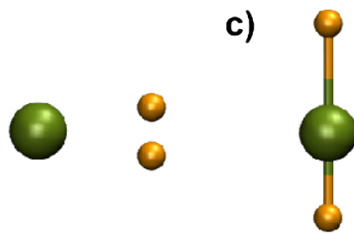

Fig. 2 Local minima of cationic $\mathrm{BeD}_{2}$ obtained with $\operatorname{CCSD}(\mathrm{T})$. a-c refer to the structures I, II, and III in the text

for the symmetric linear structure (Be-H: $\sim 1.46 \AA$ ). The bent structure (II) corresponds to the global minimum. Furthermore, only CCSDT(T) predicts another local minimum (III) for the asymmetric linear structure (Be-H: $1.323 \AA, 1.716 \AA$ ). Their structures are depicted in Fig. 2. This is in contrast with the potential energy surface of $\mathrm{BeH}_{2}^{+}$ produced at $\mathrm{CMRCI} / \mathrm{cm}^{3}-$ pVTZ level of theory in ref. [29], where only the linear asymmetric structure is reported beside the van der Waals minimum. However, only $\mathrm{BeH}_{2}^{+} \mathrm{II}$ is below the dissociation limit for $\mathrm{Be}^{+}+\mathrm{H}_{2}$. Furthermore, we optimized the equilibrium geometries of the other local minima for $\mathrm{BeH}_{2}$ and $\mathrm{BeH}_{2}^{+}$of the same publication [29] with B3LYP-D and $\operatorname{CCSD}(\mathrm{T})$ to compare and validate our approach for transition state search. The the results are in good agreement (see Table 6), except for the fact mentioned above concerning the non-existence of an asymmetric linear structure of $\mathrm{BeH}_{2}^{+}$for B3LYP-D. All methods yield similar structures for neutral and ionic $\mathrm{BeH}_{3}$ molecules (see Fig. 3). The angle formed between $\mathrm{H}-\mathrm{Be}-\mathrm{H}$ is notably different with $\sim 152^{\circ}$ for neutral molecules, $\sim 166^{\circ}$ for cations and $120^{\circ}$ for anions. The experimental BeD bond length and bond length in $\mathrm{BeD}_{2}$ are 1.342 and $1.326 \AA$, respectively [32,33].

The dissociation energy $\mathrm{D}_{0}$ for $\mathrm{BeH}$ is in the range from $\sim 198$ to $231 \mathrm{~kJ} \mathrm{~mol}^{-1}(2.0-2.4 \mathrm{eV})$ which agrees with experimental values of $221 \pm 30 \mathrm{~kJ} \mathrm{~mol}^{-1}(2.3 \pm 0.3 \mathrm{eV})$ reported by Gaydon [48], $208.4 \pm 1.0 \mathrm{~kJ} \mathrm{~mol}^{-1}(2.16 \pm 0.01 \mathrm{eV})$ by Colin [50], or the estimation of $230 \mathrm{~kJ} \mathrm{~mol}^{-1}(2.4 \mathrm{eV})$ in ref. [55]. $\mathrm{BeD}_{2}$ and $\mathrm{BeD}_{3}$ yield considerably higher atomization energies of 591-631 kJ mol${ }^{-1}(6.1-6.5 \mathrm{eV})$ and $628-680 \mathrm{~kJ} \mathrm{~mol}^{-1}$ $(6.4-7.1 \mathrm{eV})$. A similar trend is seen for positive ions, with 290-317 kJ mol${ }^{-1}(3.0-3.3 \mathrm{eV}), 362-414 \mathrm{~kJ} \mathrm{~mol}^{-1}$ (3.6$4.3 \mathrm{eV}), 822-855 \mathrm{~kJ} \mathrm{~mol}^{-1}(8.5-8.9 \mathrm{eV})$ for $\mathrm{BeD}^{+}, \mathrm{BeD}_{2}^{+} \mathrm{I}$, and $\mathrm{BeD}_{3}^{+}$, respectively. We did not calculate $\mathrm{D}_{0}$ and enthalpies of formation of negative ions. The electron affinities (EA) of $\mathrm{BeH}$ and $\mathrm{BeH}_{3}$ were calculated (see Table 4). $\mathrm{BeH}$ $\left(\mathrm{BeH}_{3}\right)$ gains about $50(275) \mathrm{kJ} \mathrm{mol}^{-1}$ by electron attachment to form $\mathrm{BeH}^{-}\left(\mathrm{BeH}_{3}{ }^{-}\right)$. The latter value agrees excellently with the calculations in ref. [35]. There is data for photodetachment of $\mathrm{BeH}^{-}$forming $\mathrm{BeH}_{2}$ via the reaction $\mathrm{BeH}^{-}+\mathrm{H}^{+} \rightarrow \mathrm{BeH}_{2}$ [56]. The authors measured the enthalpy of reaction to be $1630 \pm 13 \mathrm{~kJ} \mathrm{~mol}^{-1}$ which agrees with our calculated value of $1640-1665 \mathrm{~kJ} \mathrm{~mol}^{-1}$. The standard enthalpies of formation are similar for $\mathrm{BeD}$ and $\mathrm{BeD}_{3}$ yielding about $300-350 \mathrm{~kJ} \mathrm{~mol}^{-1}(3.1-3.6 \mathrm{eV})$. They are higher than the one for $\mathrm{BeD}_{2}$, for which $\Delta_{\mathrm{f}} \mathrm{H}^{\circ}$ is about $130-170 \mathrm{~kJ} \mathrm{~mol}^{-1}$ $(1.4-1.8 \mathrm{eV})$. The enthalpies of formation of beryllium deuterides are higher than for beryllium hydrides by $\sim 3$ to $10 \mathrm{~kJ} \mathrm{~mol}^{-1}$ (and almost the same numbers apply for cations). Overall, B3LYP-D results in higher dissociation energies than $\operatorname{CCSD}(\mathrm{T})$. This is not the case for the enthalpies of formation. The B2PLYPD functional yields values that are very close to those obtained with $\operatorname{CCSD}(\mathrm{T})$.

\section{Thermodynamics}

Standard enthalpies $\Delta_{\mathrm{r}} \mathrm{H}^{\circ}$ and the free energies $\Delta_{\mathrm{r}} \mathrm{G}^{\circ}$ of reaction were calculated for all possible dissociation channels of the stable neutral and ionic beryllium deuterides in the temperature range from 0 to $1000 \mathrm{~K}$. We selected reaction channels (Eqs. 7 and 8 ) with $\log \left(\mathrm{K}_{\mathrm{EQ}}\right)>-5$ for a further analysis of reaction pathways. The temperature dependences of the free energies of reaction are shown in Fig. 4 for the dissociation of neutral and cationic beryllium deuterides as calculated with B3LYP-D and CCSD(T). We calculated the enthalpies and the free energies of reactions for $\mathrm{BeD}$ and $\mathrm{BeD}^{+}$based on very accurate data extracted from MR ACPF calculations by Koput [22] which serve as benchmark values for our results. $\Delta_{\mathrm{r}} \mathrm{H}^{\circ}$ at $298.15 \mathrm{~K}$ and $\Delta_{\mathrm{r}} \mathrm{G}^{\circ}$ at $298.15 \mathrm{~K}$ and $1000 \mathrm{~K}$ obtained by different methods are provided for neutral molecules and cations in Tables 7 and 8, respectively. The MR ACPF enthalpies and free energies of the reactions 7.a and 8.a are very close to $\mathrm{G} 4$ and $\operatorname{CCSD}(\mathrm{T})$ values yielding differences up to $5 \mathrm{~kJ} \mathrm{~mol}^{-1}$ for $\mathrm{G} 4$ and $\operatorname{CCSD}(\mathrm{T})$ indicating that $\mathrm{BeD}$ and $\mathrm{BeD}^{+}$do not yield strong multi-referential character of the wave functions
Table 6 Bond lengths and angles of corresponding optimized structures obtained by B3LYP-D and $\operatorname{CCSD}(\mathrm{T})$ methods compared with data from ref. [29]

\begin{tabular}{|c|c|c|c|c|c|c|c|}
\hline & \multirow{2}{*}{$\frac{\text { BeH }_{\mathbf{2}} \text { linear }}{B e-H}$} & \multicolumn{2}{|c|}{$\mathrm{BeH}_{2}\left({ }^{3} \mathbf{B}_{2}\right)$} & \multicolumn{2}{|c|}{$\mathrm{BeH}_{2}^{+}$linear } & \multicolumn{2}{|c|}{$\mathrm{BeH}_{2}^{+}\left({ }^{2} \mathrm{~A}_{1}\right)$} \\
\hline & & $\mathrm{Be}-\mathrm{H}$ & $\mathrm{H}-\mathrm{Be}-\mathrm{H}$ & $R_{I}$ & $R_{2}$ & $R_{1}$ & $H-B e-H$ \\
\hline B3LYP-D & 1.324 & 1.433 & 42.3 & -- & -- & 1.877 & 23.6 \\
\hline $\operatorname{CCSD}(T)$ & 1.327 & 1.438 & 39.7 & 1.323 & 1.716 & 1.817 & 24.3 \\
\hline CASSCF & 1.330 & 1.445 & 40.0 & 1.320 & 1.731 & 1.798 & 24.6 \\
\hline CMRCI & 1.330 & 1.442 & 39.8 & 1.327 & 1.723 & 1.794 & 24.7 \\
\hline
\end{tabular}


a)

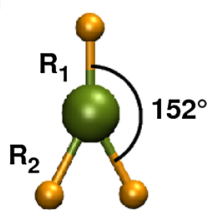

b)

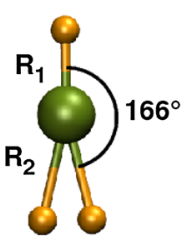

c)

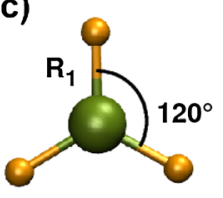

Fig. 3 Structures of a) neutral, b) cationic, and c) anionic $\mathrm{BeD}_{3}$ obtained with B3LYP-D

in equilibrium. However, this will be discussed in more detail in the next section which is dedicated to transition states.

$$
\begin{aligned}
& B e D(g) \rightarrow B e(g)+D(g) \\
& B e D_{2}(g) \rightarrow B e(g)+D_{2}(g) \\
& B e D_{2}(g) \rightarrow B e D(g)+D(g) \\
& B e D_{3}(g) \rightarrow B e D(g)+D_{2}(g) \\
& B e D_{3}(g) \rightarrow B e D_{2}(g)+D(g) \\
& B e D^{+}(g) \rightarrow B e^{+}(g)+D(g) \\
& B e D_{2}^{+}(g) I I \rightarrow B e^{+}(g)+D_{2}(g) \\
& B e D_{2}^{+}(g) I \rightarrow B e D^{+}(g)+D(g) \\
& B e D_{3}^{+}(g) \rightarrow B e D^{+}(g)+D_{2}(g)
\end{aligned}
$$

Almost all studied dissociation channels have equilibrium constants very close to $0\left(\mathrm{~K}_{\mathrm{EQ}}<<1\right)$; the reactants dominate

in the mixtures and an increase of the concentration of products leads to the production of more reactants. Reaction 7.c has a rather high $\Delta_{\mathrm{r}} \mathrm{H}^{\circ}$ value of $395 \mathrm{~kJ} \mathrm{~mol}^{-1}$ for G4 and $411 \mathrm{~kJ}$ $\mathrm{mol}^{-1}$ for B97D $(4.1-4.3 \mathrm{eV})$ at $298.15 \mathrm{~K} . \mathrm{BeD}_{2}$ more likely dissociates into $\mathrm{Be}$ and $\mathrm{D}_{2}$ with $\Delta_{\mathrm{r}} \mathrm{H}^{\circ}(298.15 \mathrm{~K})=188.0 \mathrm{~kJ}$ $\mathrm{mol}^{-1}$ for B3LYP-D. The change of standard free energy predicts $\log \left(\mathrm{K}_{\mathrm{EQ}}\right)>-5$ for more than $\sim 800 \mathrm{~K}$. For $\mathrm{BeD}_{3}$, both channels (7.d and 7.e) have similar characteristics with $\Delta_{\mathrm{r}} \mathrm{G}^{\circ}$ (T) close to $0 \mathrm{~kJ} \mathrm{~mol}^{-1}$ already at $0 \mathrm{~K} \cdot \Delta_{\mathrm{r}} \mathrm{G}^{\circ}$ (T) for dissociation of $\mathrm{BeD}$ lies in the range of 203-237 kJ mol${ }^{-1}(2.1-2.5 \mathrm{eV})$ at $298.15 \mathrm{~K} . \mathrm{BeD}^{+}$has the highest $\Delta_{\mathrm{r}} \mathrm{G}^{\circ}(\mathrm{T})$ of the reported cations. 8.b is the preferable channel of the two most likely ways of the dissociation of $\mathrm{BeD}_{2}^{+}\left(\Delta_{\mathrm{r}} \mathrm{G}^{\circ}<0\right.$ already at $\left.300 \mathrm{~K}\right)$. The second channel, reaction 8.c, has a lower $\Delta_{\mathrm{r}} \mathrm{H}^{\circ}$ than its neutral alternative: $76-106 \mathrm{~kJ} \mathrm{~mol}^{-1}$ at $298.15 \mathrm{~K}(0.7-1.1 \mathrm{eV})$ with $\log \left(\mathrm{K}_{\mathrm{EQ}}\right)<-5$ at $\sim 500 \mathrm{~K}$. There is only one channel (8.d) with $\Delta_{\mathrm{r}} \mathrm{H}^{\circ}=91-100 \mathrm{~kJ} \mathrm{~mol}^{-1}(0.9-1.0 \mathrm{eV})$ for $\mathrm{BeD}_{3}^{+}$as the others all have a $\log \left(\mathrm{K}_{\mathrm{EQ}}\right)<-5$. This reaction has $\log \left(\mathrm{K}_{\mathrm{EQ}}\right)>-5$ from $\sim 500 \mathrm{~K}$ on.

\section{Reactivity of beryllium deuterides}

The structural properties and the free energy of activation $\Delta \mathrm{G}^{\ddagger}$ of transition states obtained using the $\operatorname{CCSD}(\mathrm{T})$ method for the forward and reverse reactions along each channel are presented in Tables 9 and 10, respectively. Their structures are depicted in Fig. 5. Reaction rate constants can be calculated
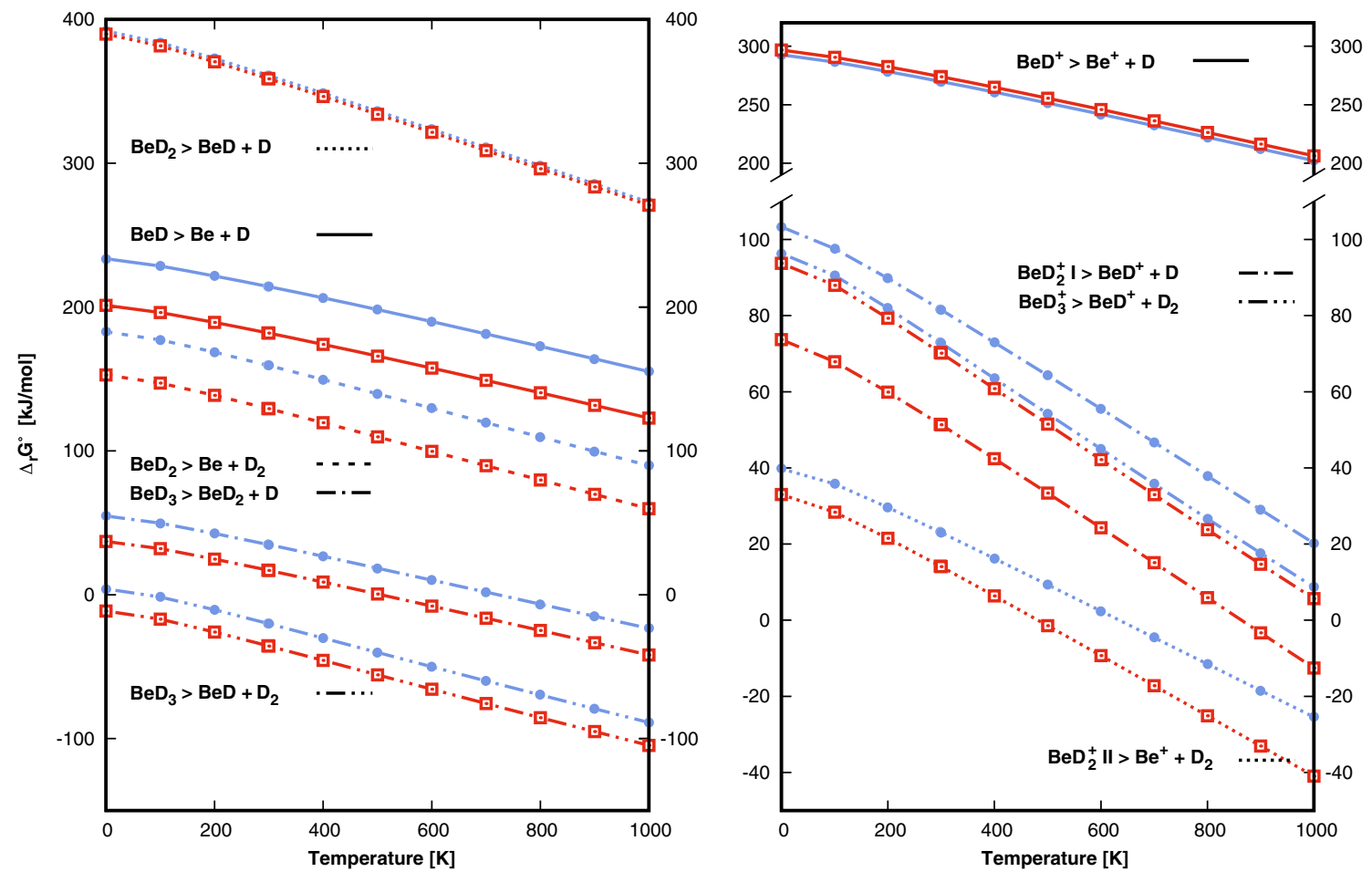

Fig. 4 Changes of the standard free energies of reaction for a) neutral and b) positive beryllium deuterides given by B3LYP-D (full circle) and CCSD(T) (empty square) methods 
Table 7 Changes of the enthalpy of reaction at $298.15 \mathrm{~K}$ and changes of the free energy of reaction at 298.15 and $1000 \mathrm{~K}$ for the dissociation of neutral beryllium deuterides obtained from various methods. MR ACPF values are calculated from data in ref. [22]. All values are in $\mathrm{kJ} \mathrm{mol}^{-1}$. The threshold temperature $T_{k}$ for crossing the $\log \left(\mathrm{K}_{\mathrm{EQ}}\right)>-5$ limit is also given

\begin{tabular}{|c|c|c|c|c|c|c|c|c|c|c|c|c|c|c|c|}
\hline \multirow{3}{*}{$\begin{array}{l}\text { Method } \\
\text { T[K] }\end{array}$} & \multicolumn{3}{|c|}{$\begin{array}{l}B e D(g) \rightarrow \\
B e(g)+D(g)\end{array}$} & \multicolumn{3}{|c|}{$\begin{array}{l}\mathrm{BeD}_{2}(\mathrm{~g}) \rightarrow \\
\mathrm{Be}(\mathrm{g})+\mathrm{D}_{2}(\mathrm{~g})\end{array}$} & \multicolumn{3}{|c|}{$\begin{array}{l}\mathrm{BeD}_{2}(\mathrm{~g}) \rightarrow \\
\mathrm{BeD}(\mathrm{g})+\mathrm{D}(\mathrm{g})\end{array}$} & \multicolumn{3}{|c|}{$\begin{array}{l}\mathrm{BeD}_{3}(\mathrm{~g}) \rightarrow \\
\mathrm{BeD}(\mathrm{g})+\mathrm{D}_{2}(\mathrm{~g})\end{array}$} & \multicolumn{3}{|c|}{$\begin{array}{l}\mathrm{BeD}_{3}(\mathrm{~g}) \rightarrow \\
\mathrm{BeD}_{2}(\mathrm{~g})+\mathrm{D}(\mathrm{g})\end{array}$} \\
\hline & \multirow[t]{2}{*}{$\Delta_{r} H^{\circ}$} & \multicolumn{2}{|l|}{$\Delta_{r} \boldsymbol{G}^{\circ}$} & \multirow[t]{2}{*}{$\Delta_{r} \boldsymbol{H}^{\circ}$} & \multicolumn{2}{|l|}{$\Delta_{r} \boldsymbol{G}^{\circ}$} & \multirow[t]{2}{*}{$\Delta_{r} \boldsymbol{H}^{\circ}$} & \multicolumn{2}{|l|}{$\Delta_{r} \boldsymbol{G}^{\circ}$} & \multirow[t]{2}{*}{$\Delta_{r} \boldsymbol{H}^{\circ}$} & \multicolumn{2}{|l|}{$\Delta_{r} \boldsymbol{G}^{\circ}$} & \multirow[t]{2}{*}{$\Delta_{r} \boldsymbol{H}^{\circ}$} & \multicolumn{2}{|l|}{$\Delta_{r} \boldsymbol{G}^{\circ}$} \\
\hline & & 298.15 & 1000 & & 298.15 & 1000 & & 298.15 & 1000 & & 298.15 & 1000 & & 298.15 & 1000 \\
\hline B3LYP-D & 237.3 & 214.4 & 155.2 & 188.0 & 159.5 & 89.8 & 397.3 & 361.2 & 273.0 & 9.5 & -20.0 & -88.8 & 58.7 & 35.0 & -23.4 \\
\hline B97D & 216.4 & 193.6 & 134.7 & 174.0 & 145.6 & 76.3 & 410.7 & 374.6 & 286.5 & 11.7 & -17.6 & -85.9 & 54.1 & 30.5 & -27.4 \\
\hline B2PLYPD & 228.6 & 205.67 & 146.4 & 183.5 & 154.9 & 85.2 & 394.9 & 358.8 & 270.5 & 2.8 & -26.8 & -96.1 & 47.9 & 24.0 & -34.8 \\
\hline M06 & 231,9 & 209.0 & 149.7 & 202.6 & 174.1 & 104.6 & 407.6 & 371.6 & 283.7 & 5.4 & -23.9 & -92.1 & 34.7 & 11.0 & -47.0 \\
\hline G4 & 211,0 & 188.1 & 128.9 & 161.1 & 132.5 & 62.5 & 395.0 & 358.8 & 270.3 & -9.8 & -39.4 & -108.8 & 40.1 & 15.4 & -43.7 \\
\hline $\operatorname{CCSD}(\mathrm{T})$ & 204.5 & 182.1 & 122.8 & 158.0 & 129.5 & 59.9 & 395.0 & 358.9 & 270.8 & -5.9 & -35.5 & -104.8 & 31.0 & 17.1 & -41.8 \\
\hline MR ACPF & 206.6 & 186.4 & 131.9 & --- & --- & --- & --- & --- & --- & --- & --- & --- & --- & --- & -- \\
\hline $\mathbf{T}_{\mathbf{k}}[\mathbf{K}]$ & & -- & & $\sim 800$ & & & -- & & & alread & at 0 & & $\sim 200$ & & \\
\hline
\end{tabular}

using Eq. 6. The rate constants in the linear form of the Eyring-Polanyi equation for channels with identified transition states of Eqs. 7 are plotted in Fig. 6.

\section{$\mathrm{BeD}$ and $\mathrm{BeD}^{+}$}

We did not find any transition state concerning the dissociation of $\mathrm{BeH}$ or $\mathrm{BeH}^{+}$in line with earlier studies [22-24].

\section{$\mathrm{BeD}_{2}$ and $\mathrm{BeD}_{2}^{+}$}

A more complex behavior is found for the reactivity of neutral and cationic $\mathrm{BeD}_{2}$. Beryllium dihydride can dissociate into $\mathrm{Be}$ $+\mathrm{D}_{2}$ through the transition state $\mathrm{TS}_{1}$, which corresponds to the

Table 8 Changes of the standard enthalpy of reaction at $298.15 \mathrm{~K}$ and changes of the standard free energy of reaction at 298.15 and $1000 \mathrm{~K}$ for dissociation of cationic beryllium deuterides obtained or crossing $\log \left(\mathrm{K}_{\mathrm{EQ}}\right)>-5$ limit is also presented one found in ref. [29]. No transition state was found for the other channel (7.c) in the ground state, but we localized one $\left(\mathrm{TS}_{2}\right)$ in the triplet state. $\operatorname{CCSD}(\mathrm{T})$ yields the same transition state structures as B3LYP-D. Both transition states are very close in energy and in the region where the ground state potential energy surface intersects the one of the triplet state. Therefore, their activation free energies are similar and rather high, $\sim 380 \mathrm{~kJ} \mathrm{~mol}^{-1}(3.9 \mathrm{eV})$, with regard to the $\mathrm{BeD}_{2}$ ground state. $\mathrm{TS}_{2}$ is about $55 \mathrm{~kJ} \mathrm{~mol}^{-1}(0.6 \mathrm{eV})$ higher than the triplet state local minima and about $30 \mathrm{~kJ} \mathrm{~mol}^{-1}(0.3 \mathrm{eV})$ below the plateau of the excited $\mathrm{Be}+\mathrm{D}_{2}$ complex. We assume that the channel resulting in $\mathrm{Be}+\mathrm{D}_{2}$ is preferable in general, however, in a fusion plasma environment the required excitation energy is easily reachable and dissociation into $\mathrm{BeD}+\mathrm{D}$ is therefore

from various methods. MR ACPF values are calculated from data in ref. [23]. All values are in $\mathrm{kJ} \mathrm{mol}^{-1}$. The values for the bent structure of $\mathrm{BeD}_{2}^{+}$are used here. The threshold temperature $T_{k} f$

\begin{tabular}{|c|c|c|c|c|c|c|c|c|c|c|c|c|}
\hline \multirow{3}{*}{$\begin{array}{l}\text { Method } \\
\text { T[K] }\end{array}$} & \multicolumn{3}{|c|}{$\begin{array}{l}\mathrm{BeD}^{+}(\mathrm{g}) \rightarrow \\
\mathrm{Be}^{+}(\mathrm{g})+\mathrm{D}(\mathrm{g})\end{array}$} & \multicolumn{3}{|c|}{$\begin{array}{l}\mathrm{BeD}_{2}^{+}(\mathrm{g}) \boldsymbol{I I} \rightarrow \\
\quad \boldsymbol{B e}^{+}(\mathrm{g})+\mathrm{D}_{2}(\mathrm{~g})\end{array}$} & \multicolumn{3}{|c|}{ 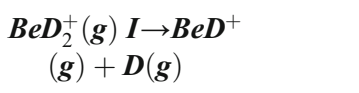 } & \multicolumn{3}{|c|}{$\begin{array}{c}\mathrm{BeD}_{3}^{+}(\mathrm{g}) \rightarrow \boldsymbol{B e D} D^{+} \\
(\mathrm{g})+\mathrm{D}_{2}(\mathrm{~g})\end{array}$} \\
\hline & \multirow[t]{2}{*}{$\Delta_{r} \boldsymbol{H}^{\circ}$} & \multicolumn{2}{|l|}{$\Delta_{r} \boldsymbol{G}^{\circ}$} & \multirow[t]{2}{*}{$\Delta_{r} \boldsymbol{H}^{\circ}$} & \multicolumn{2}{|l|}{$\Delta_{r} \boldsymbol{G}^{\circ}$} & \multirow[t]{2}{*}{$\Delta_{r} \boldsymbol{H}^{\circ}$} & \multicolumn{2}{|l|}{$\Delta_{r} \boldsymbol{G}^{\circ}$} & \multirow[t]{2}{*}{$\Delta_{r} \boldsymbol{H}^{\circ}$} & \multicolumn{2}{|l|}{$\Delta_{r} \boldsymbol{G}^{\circ}$} \\
\hline & & 298.15 & 1000 & & 298.15 & 1000 & & 298.15 & 1000 & & 298.15 & 1000 \\
\hline B3LYP-D & 296.4 & 269.9 & 202.2 & 43.3 & 23.1 & -25.5 & 106.5 & 81.2 & 19.4 & 99.8 & 70.5 & 2.0 \\
\hline B97D & 320.5 & 294.1 & 226.5 & 37.4 & 16.2 & -35.0 & 101.2 & 75.9 & 13.9 & 91.5 & 64.4 & 1.5 \\
\hline B2PLYPD & 293.0 & 266.5 & 198.7 & 38.7 & 16.4 & -37.8 & 92.2 & 66.4 & 3.2 & 99.7 & 72.0 & 7.4 \\
\hline M06 & 310.3 & 283.9 & 216.1 & 36.4 & 14.2 & -39.8 & 84.5 & 58.5 & -5.6 & 97.1 & 70.0 & 7.0 \\
\hline G4 & 304.8 & 278.4 & 210.8 & 39.6 & -17.5 & -35.9 & 76.0 & 50.9 & -10.6 & 97.3 & 69.4 & 4.4 \\
\hline $\operatorname{CCSD}(T)$ & 300.5 & 274.1 & 206.3 & 36.9 & -14.2 & -41.0 & 77.6 & 51.5 & -12.6 & 98.0 & 70.3 & 5.7 \\
\hline MR ACPF & 301.9 & 278.9 & 215.5 & --- & --- & --- & --- & --- & --- & --- & --- & --- \\
\hline $\mathbf{T}_{\mathbf{k}}[\mathbf{K}]$ & -- & & & $\sim 300$ & & & $\sim 400$ & & & $\sim 500$ & & \\
\hline
\end{tabular}


Table 9 Bond lengths and angles of the transition states obtained by $\operatorname{CCSD}(\mathrm{T})$ for studied dissociation channels in Eqs. 7 and 8. The lengths are given in $\AA$, angles in degrees. These structures are presented in Fig. 5

\begin{tabular}{|c|c|c|c|c|c|}
\hline & \multicolumn{2}{|l|}{$\mathrm{BeH}_{2}$} & \multicolumn{3}{|l|}{$\mathrm{BeH}_{3}$} \\
\hline & $T S_{I}$ & $T S_{2}$ & $T S_{3}$ & $T S_{4}$ & $I M$ \\
\hline Be-H1 & 1.379 & 1.344 & 1.323 & 1.340 & 1.339 \\
\hline $\mathrm{Be}-\mathrm{H} 2$ & 1.646 & 2.827 & 1.403 & 1.852 & 1.714 \\
\hline Be-H3 & --- & --- & 1.498 & 1.917 & 1.776 \\
\hline $\mathrm{H} 1-\mathrm{Be}-\mathrm{H} 2$ & 43.5 & 67.5 & 161.2 & 109.5 & 113.5 \\
\hline H1-Be-H3 & --- & --- & 123.4 & 86.3 & 87.9 \\
\hline
\end{tabular}

also possible. The difference of $\Delta \mathrm{G}^{\ddagger}$ for the two transition states, $\sim 20 \mathrm{~kJ} \mathrm{~mol}^{-1}(0.2 \mathrm{eV})$ in the range $0-1000 \mathrm{~K}$, favors decomposition into $\mathrm{BeD}+\mathrm{D}$. The reverse reaction 7.b has a high barrier as well, $\sim 260 \mathrm{~kJ} \mathrm{~mol}^{-1}(2.7 \mathrm{eV})$ at $298.15 \mathrm{~K}^{-1}$ and $\sim 320 \mathrm{~kJ} \mathrm{~mol}^{-1}(3.3 \mathrm{eV})$ at $1000 \mathrm{~K}$. We could not identify any transition state for channels 8.b and 8.c with $\operatorname{CCSD}(\mathrm{T})$. Still, $\mathrm{BeD}_{2}^{+}$is predicted to dissociate into $\mathrm{Be}^{+}+\mathrm{D}_{2}$ due to the negative free reaction energy already at $300 \mathrm{~K}$.

\section{$\mathrm{BeD}_{3}$ and $\mathrm{BeD}_{3}^{+}$}

The $\mathrm{BeD}_{3}$ molecule is metastable. We found a two-step reaction mechanism for reaction 7.d. However, the intermediate (IM) and the transition state $\mathrm{TS}_{4}$ (see Fig. 4) are very close in energy and similar in structure and are also lower in energy than the local minima at higher temperatures. Thus, they make the decomposition into $\mathrm{BeD}+\mathrm{D}_{2}$ more likely than the competing reaction 7.e. The free activation energies, $\Delta \mathrm{G}^{\ddagger}$, for these barriers are $\sim 14 \mathrm{~kJ} \mathrm{~mol}^{-1}(0.1 \mathrm{eV})$ at $298.15 \mathrm{~K}$ and $~$ $-0.5 \mathrm{~kJ} \mathrm{~mol}^{-1}(0.01 \mathrm{eV})$ at 298.15 for $\mathrm{TS}_{3}$ and $\mathrm{TS}_{4}$, respectively. B3LYP-D predicts the same characteristics of the transition states as $\operatorname{CCSD}(\mathrm{T})$. We did not identify any transition state for the reaction in Eq. 8.d. In fact, $\mathrm{BeD}_{3}{ }^{+}$seems to dissociate most likely into $\mathrm{BeD}^{+}+\mathrm{D}_{2}$ as this channel is energetically preferable $\left(\Delta_{\mathrm{r}} \mathrm{G}^{\circ} \sim 0\right.$ at $\left.1000 \mathrm{~K}\right)$.

The transition states found using B3LYP-D and CCSD(T) were also investigated for their multi-referential character
$\mathrm{TS}_{1}$

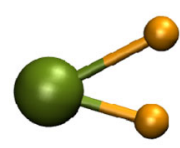

$\mathrm{TS}_{3}$

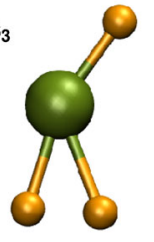

$\mathrm{TS}_{4}$
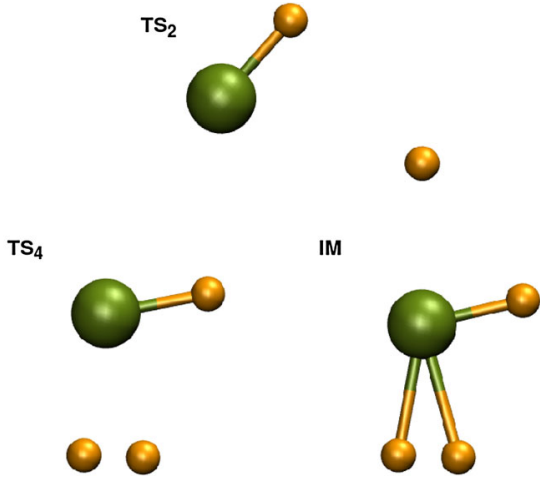

Fig. 5 Structures of the transition states for dissociation channels 7.b-d

using the $\mathrm{D}_{1}$ and $\mathrm{T} 1$ diagnostics $[57,58]$. The results are in excellent agreement with those of higher-order correlation methods if $\mathrm{D}_{1}<0.03$. If $\mathrm{D}_{1}<0.05$, the method still performs well. However, a multi-reference character of the ground-state introduced by strong orbital relaxation effects is indicated by larger values of $D_{1}$. Similarly, if $T_{1}>0.02$, the system should be investigated by a multi-reference electron correlation method. The conclusion of the $\mathrm{D}_{1}$ and $\mathrm{T}_{1}$ diagnostics for $\mathrm{BeH}$ molecules is as follows: all equilibrium structures have $\mathrm{D}_{1}$ less than 0.03 and $\mathrm{T}_{1}<0.02$, except asymmetric linear $\mathrm{BeD}_{2}^{+}$ $\left(\mathrm{T}_{1}=0.02, \mathrm{D}_{1}=0.08\right)$, thus $\operatorname{CCSD}(\mathrm{T})$ should describe their ground states reliably. Far from equilibrium and for some transition states these diagnostics yield higher values, indicating that single-reference methods could become inadequate for describing these states. This concerns only transition states for neutral and positive $\mathrm{BeH}_{2}\left(\mathrm{~T}_{1} \sim 0.35, \mathrm{D}_{1} \sim 0.08\right)$. Transition states related to $\mathrm{BeH}_{3}$ molecules yield $\mathrm{D}_{1}<0.03$, with minimum and maximum values of 0.015 and 0.029 , respectively, and $\mathrm{T}_{1} \sim 0.01$. Further investigations are required to scrutinize how the various PESs and energetics are affected by more accurate correlation and multi-referential character, which we plan to do in a following work.

\section{Production of $B e D$}

Analysis of our MD simulations yields that sputtering of $\mathrm{BeD}$ can often be described by the following reactions (9.a and 9.b)
Table 10 Activation energies $\Delta \mathrm{G}^{\ddagger}$ corresponding to the transition states TS for the dissociation channels of the beryllium deuterides at $298.15 \mathrm{~K}$, $600 \mathrm{~K}$, and $1000 \mathrm{~K}$ for the forward and reverse reactions obtained by the $\operatorname{CCSD}(\mathrm{T})$ method

\begin{tabular}{|c|c|c|c|c|c|c|c|}
\hline \multirow[b]{3}{*}{$\mathrm{T}[\mathrm{K}]$} & \multirow[t]{3}{*}{ Transition state } & \multicolumn{3}{|c|}{ Forward } & \multicolumn{3}{|c|}{ Reverse } \\
\hline & & \multicolumn{3}{|c|}{$\Delta \mathrm{G}^{\ddagger}\left[\mathrm{kJ} \mathrm{mol}^{-1}\right]$} & \multicolumn{3}{|c|}{$\Delta \mathrm{G}^{\ddagger}\left[\mathrm{kJ} \mathrm{mol}^{-1}\right]$} \\
\hline & & 298.15 & 600 & 1000 & 298.15 & 600 & 1000 \\
\hline$B e D_{2}(g) \rightarrow B e(g)+D_{2}(g)$ & $\mathrm{TS}_{1}$ & 392.6 & 385.8 & 377.8 & 263.1 & 286.0 & 317.9 \\
\hline$B e D_{2}(g) \rightarrow B e D(g)+D(g)$ & $\mathrm{TS}_{2}$ & 377.4 & 362.9 & 344.6 & 18.5 & 41.4 & 73.8 \\
\hline \multirow[t]{2}{*}{$B e D_{3}(g) \rightarrow B e D(g)+D_{2}(g)$} & $\mathrm{TS}_{3}$ & 13.4 & 16.3 & 22.4 & 48.9 & 82.0 & 127.2 \\
\hline & $\mathrm{TS}_{4}$ & -0.5 & -1.3 & -0.6 & 34.9 & 64.4 & 104.2 \\
\hline
\end{tabular}




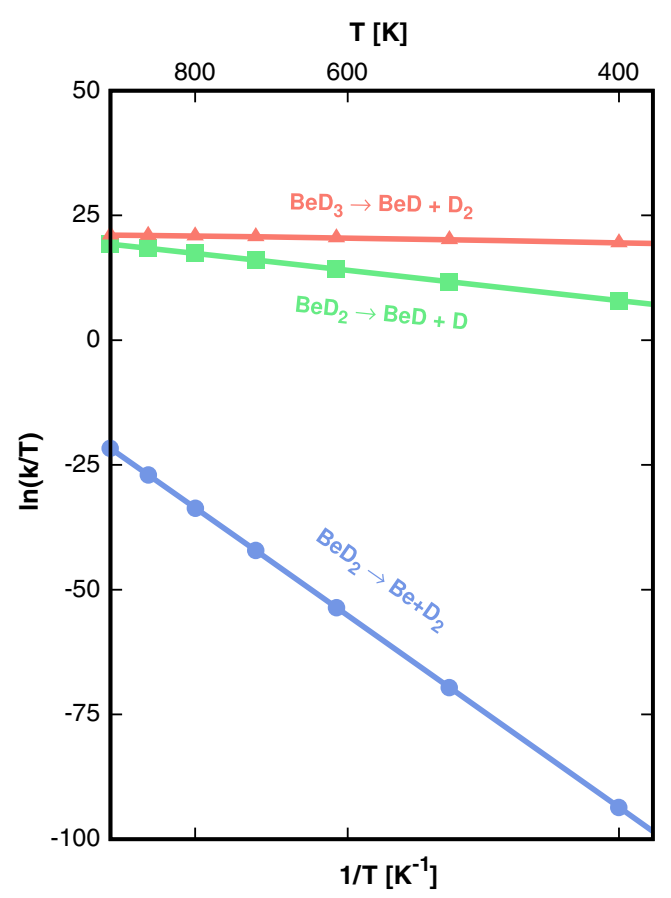

Fig. 6 Dependence of reaction rates on temperature in the linear form of Eyring equation (Eq. 6.b) for channels with identified transition states

ignoring the surrounding surface atoms. $\mathrm{BeD}_{2}$ and $\mathrm{BeD}_{3}$ turn out to be intermediate products that last only for a few steps.

$$
\begin{aligned}
& B_{e} D_{2}(g)+D(g) \rightarrow B^{2} D_{3}(g) \rightarrow B e D(g)+D_{2}(g) \\
& B e(g)+D_{2}(g) \rightarrow B e D_{2}(g) \rightarrow B e D(g)+D(g)
\end{aligned}
$$

The reaction 9.b without the intermediate $\mathrm{BeD}_{2}$ was also suggested and analyzed by Nishijima et al. [55]. However, the ionic reaction $\mathrm{Be}^{+}+\mathrm{D}_{2}$ was shown to dominate the production of $\mathrm{BeD}^{+}$inside a plasma column. Based on our calculated standard free energies of reaction and reaction schemes for $\mathrm{BeD}_{2}$ and $\mathrm{BeD}_{3}$ we can determine the reactivity of the proposed reactions in Eq. 9. $\mathrm{BeD}_{2}$ and $\mathrm{D}$ can easily form the $\mathrm{BeD}_{3}$ intermediate dissociating subsequently into $\mathrm{BeD}+\mathrm{D}_{2}$. Impinging particles with small kinetic energy could possibly lead to $\mathrm{BeD}$ and $\mathrm{D}_{2}$ via this reaction pathway. The other reaction, 9.b, has a high barrier for all studied temperatures, but it is a possible reaction nonetheless. Concerning the production of $\mathrm{BeD}$ from the surface, reaction 9.b is slower than 9.a and higher impact energies are needed.

\section{Conclusions}

We report reaction schemes of the dissociation of small beryllium deuterides based on calculated thermodynamic properties, standard enthalpies of formation, and standard enthalpies and free energies of reaction as obtained by quantum-chemical methods. Transition state theory was used to determine the rate constants for the considered reactions. $\mathrm{BeD}$ and $\mathrm{BeD}^{+}$ are the most stable species, unlikely to further dissociate into their components. $\mathrm{BeD}_{2}$ and $\mathrm{BeD}_{2}^{+}$are more likely to decompose into $\mathrm{Be}+\mathrm{D}_{2}$ than into $\mathrm{BeD}+\mathrm{D} . \mathrm{BeD}_{3}$ and $\mathrm{BeD}_{3}^{+}$are metastable against their dissociation into $\mathrm{BeD}+\mathrm{D}_{2}$. Concerning the source of beryllium hydride production, we performed MD simulations of low energy $\mathrm{D}$ irradiation on $\mathrm{Be}$ surfaces to obtain the details of the sputtering events and analyzed these events from thermodynamic and kinetic points of view. The analysis of the MD trajectories confirms that the formation of $\mathrm{BeD}$ occurs along the reaction pathways that have been suggested before.

Acknowledgment Open access funding provided by Austrian Science Fund (FWF). All authors contributed equally to the paper.

This work was supported by the Austrian Science Fund (FWF): P28979-N27 and was carried out within the framework of the EUROfusion Consortium and has received funding from the Euratom research and training programme 2014-2018 under grant agreement No 633053. The views and opinions expressed herein do not necessarily reflect those of the European Commission. The computational results presented have been achieved (in part) using the HPC infrastructure LEO of the University of Innsbruck. The work was also funded by Scientific Grant Agency of Ministry of Education SR and Slovak Academy of Sciences (VEGA): 1/0878/15.

Open Access This article is distributed under the terms of the Creative Commons Attribution 4.0 International License (http:// creativecommons.org/licenses/by/4.0/), which permits unrestricted use, distribution, and reproduction in any medium, provided you give appropriate credit to the original author(s) and the source, provide a link to the Creative Commons license, and indicate if changes were made.

\section{References}

1. Pitts RA, Carpentier S, Escourbiac F, Hirai T, Komarov V, Kukushkin AS, Lisgo S, Loarte A, Merola M, Mitteau R, Raffray AR, Shimada M, Stangeby PC (2011) Physics basis and design of the ITER plasma-facing components. J Nucl Mater 415:S957S964

2. Doerner RP, Baldwin MJ, Buchenauer D, De Temmerman G, Nishijima D (2009) The role of beryllium deuteride in plasmaberyllium interactions. J Nucl Mater 390-391:681-684. doi:10. 1016/j.jnucmat.2009.01.187

3. Nishijima D, Doerner RP, Baldwin MJ, De Temmerman G (2009) Erosion yields of deposited beryllium layers. J Nucl Mater 390 391:132-135. doi:10.1016/j.jnucmat.2009.01.144

4. Dittmar T, Baldwin MJ, Doerner RP, Nishijima D, Oberkofler M, Schwarz-Selinger T, Tabarés F (2011) Interaction of high flux deuterium/nitrogen plasmas with beryllium. Phys Scr 145:14009. doi:10.1088/0031-8949/2011/T145/014009

5. Oberkofler M, Linsmeier C (2010) Properties of nitrogenimplanted beryllium and its interaction with energetic deuterium. Nucl Fusion 50:125001. doi:10.1088/0029-5515/50/12/125001

6. Oberkofler M, Reinelt M, Linsmeier C (2011) Retention and release mechanisms of deuterium implanted into beryllium. Nucl Instruments Methods Phys Res Sect B Beam Interact with Mater Atoms 269:1266-1270. doi:10.1016/j.nimb.2010.11.058

7. Stamp MF, Krieger K, Brezinsek S (2011) Measurements of beryllium sputtering yields at JET. J Nucl Mater 415:S170-S173. doi:10. 1016/j.jnucmat.2010.12.038 
8. Schmid K, Krieger K, Lisgo SW, Meisl G, Brezinsek S, Contributors JET (2015) WALLDYN simulations of global impurity migration in JET and extrapolations to ITER. Nucl Fusion 55: 53015. doi:10.1088/0029-5515/55/5/053015

9. Kirschner A, Philipps V, Winter J, Kögler U (2002) Simulation of the plasma-wall interaction in a tokamak with the Monte Carlo code ERO-TEXTOR. Nucl Fusion 40:989-1001. doi:10.1088/0029$5515 / 40 / 5 / 311$

10. Möller W, Eckstein W, Biersack JP (1988) Tridyn-binary collision simulation of atomic collisions and dynamic composition changes in solids. Comput Phys Commun 51:355-368. doi:10.1016/00104655(88)90148-8

11. Eckstein W, Dohmen R, Mutzke A, Schneider R (2007) SDTrimSP: a Monte-Carlo code for calculating collision phenomena in radomized targets. Max-Planck-Institut für Plasmaphysik, Garching

12. Björkas C, Borodin D, Kirschner A, Janev RK, Nishijima D, Doerner R, Nordlund K (2013) Molecules can be sputtered also from pure metals: sputtering of beryllium hydride by fusion plasma-wall interactions. Plasma Phys Control Fusion 55:74004. doi: 10.1088/0741-3335/55/7/074004

13. Borodin D, Kirschner A, Carpentier-Chouchana S, Pitts RA, Lisgo S, Björkas C, Stangeby PC, Elder JD, Galonska A, Matveev D, Philipps V, Samm U (2011) ERO code benchmarking of ITER first wall beryllium erosion/re-deposition against LIM predictions. Phys Scr T145:14008. doi:10.1088/0031-8949/2011/T145/014008

14. Doerner RP, Björkas C, Nishijima D, Schwarz-Selinger T (2013) Erosion of beryllium under high-flux plasma impact. J Nucl Mater 438:Suppl:S272-Suppl:S275. doi:10.1016/j.jnucmat.2013.01.045

15. Björkas C, Vörtler K, Nordlund K, Nishijima D, Doerner R (2009) Chemical sputtering of be due to D bombardment. New J Phys 11: 123017. doi:10.1088/1367-2630/11/12/123017

16. Juslin N, Erhart P, Träskelin P, Nord J, Henriksson KOE, Nordlund K, Salonen E, Albe K (2005) Analytical interatomic potential for modeling nonequilibrium processes in the W-C-H system. J Appl Phys 98:1-12. doi:10.1063/1.2149492

17. Björkas C, Juslin N, Timko H, Vörtler K, Nordlund K, Henriksson K, Erhart P (2009) Interatomic potentials for the be-C-H system. J Phys Condens Matter 21:445002. doi:10.1088/0953-8984/21/44/ 445002

18. Björkas C, Borodin D, Kirschner A, Janev RK, Nishijima D, Doerner R, Nordlund K (2013) Multiscale modeling of BeD release and transport in PISCES-B. J Nucl Mater 438:Suppl:S276-Suppl: S279. doi:10.1016/j.jnucmat.2013.01.039

19. Safi E, Björkas C, Lasa A, Nordlund K, Sukuba I, Probst M (2015) Atomistic simulations of the effect of reactor-relevant parameters on be sputtering. J Nucl Mater 463:805-809

20. Virot F, Barrachin M, Souvi S, Cantrel L (2014) Theoretical prediction of thermodynamic properties of tritiated beryllium molecules and application to ITER source term. Fusion Eng Des 89: 1544-1550. doi:10.1016/j.fusengdes.2014.01.031

21. Szalay PG, Bartlett RJ (1993) Multi-reference averaged quadratic coupled-cluster method: a size-extensive modification of multireference CI. Chem Phys Lett 214:481-488. doi:10.1016/00092614(93)85670-J

22. Koput J (2013) Ab initio ground-state potential energy functions of beryllium monohydride ions: $\mathrm{BeH}+$ and $\mathrm{BeH}-$. J Chem Phys. doi: $10.1063 / 1.4820403$

23. Koput J (2011) The ab initio ground-state potential energy function of beryllium monohydride. BeH. J Chem Phys. doi:10.1063/1. 3671610

24. Bubin S, Adamowicz L (2007) Calculations of the ground states of $\mathrm{BeH}$ and $\mathrm{BeH}^{+}$without the born-Oppenheimer approximation. $\mathrm{J}$ Chem Phys doi:10.1063/1.2736699

25. Smith GS, Johnson QC, Smith DK, Cox DE, Snyder RL, Zhou R-S, Zalkin A (1988) The crystal and molecular structure of beryllium hydride. Solid State Commun. 67:491-494. doi:10.1016/00381098(84)90168-6

26. Penotti FE (2006) Electronic structure of BeH2. Int J Quantum Chem 106:1153-1159. doi:10.1002/qua.20868

27. Klein RA, Zottola MA (2006) Pople versus Dunning basis-sets for group $\{\mathrm{IA}\}$ metal hydrides and some other second row hydrides: the case against a de facto standard. Chem Phys Lett 419:254-258. doi:10.1016/j.cplett.2005.11.083

28. Martin JML (1998) Benchmark ab initio potential curves for the light diatomic hydrides. Unusually large nonadiabatic effects in BeH and BH. Chem Phys Lett 283:283-293. doi:10.1016/S00092614(97)01400-0

29. Hinze J, Friedrich O, Sundermann A (2017) A study of some unusual hydrides: $\mathrm{BeH} 2, \mathrm{BeH}+6$ and SH6. doi: 10.1080/ 00268979909483007

30. Koput J, Peterson KA (2006) Ab initio prediction of the potential energy surface and vibration-rotation energy levels of $\mathrm{BeH} 2 . \mathrm{J}$ Chem Phys 125:44306. doi:10.1063/1.2212932

31. Bernath PF, Shayesteh A, Tereszchuk K, Colin R (2002) The vibration-rotation emission spectrum of free $\mathrm{BeH} 2$. Science 297: 1323-1324. doi:10.1126/science. 1074580

32. Shayesteh A, Tereszchuk K, Bernath PF, Colin R (2003) Infrared emission spectra of BeH and BeD. J Chem Phys 118:1158-1161. doi:10.1063/1.1528606

33. Shayesteh A, Tereszchuk K, Bernath PF, Colin R (2003) Infrared emission spectra of BeH2 and BeD2. J Chem Phys 118:3622-3627. doi:10.1063/1.1539850

34. Wang X, Andrews L (2005) One-dimensional BeH2 polymers: Infrared spectra and theoretical calculations. Inorg Chem 44:610 614. doi:10.1021/ic048464b

35. Boldyrev AI, Simons J (1993) Vertical and adiabatical ionization potentials of $\mathrm{MH}-\mathrm{K}+1$ anions. Ab initio study of the structure and stability of hypervalent MHk+1 molecules. J Chem Phys 99:4628. doi:10.1063/1.466061

36. Curtiss LA, Redfern PC, Raghavachari K (2007) Gaussian-4 theory. J Chem Phys doi:10.1063/1.2436888

37. Becke AD (1993) Density-functional thermochemistry. III. The role of exact exchange. J Chem Phys 98:5648. doi:10.1063/1. 464913

38. Lee C, Yang W, Parr RG (1988) Development of the Colle-Salvetti correlation-energy formula into a functional of the electron density. Phys Rev B Condens Matter 37:785-789

39. Grimme S, Antony J, Ehrlich S, Krieg H (2010) A consistent and accurate $a b$ initio parametrization of density functional dispersion correction (DFT-D) for the 94 elements H-Pu. J Chem Phys 132: 154104. doi:10.1063/1.3382344

40. Zhao Y, Truhlar DG (2008) The M06 suite of density functionals for main group thermochemistry, thermochemical kinetics, noncovalent interactions, excited states, and transition elements: two new functionals and systematic testing of four M06-class functionals and 12 other functionals. Theor. Chem. Accounts 120:215241. doi:10.1007/s00214-007-0310-x

41. Grimme S (2006) Semiempirical hybrid density functional with perturbative second-order correlation. J Chem Phys doi:10.1063/ 1.2148954

42. Schwabe T, Grimme S (2007) Double-hybrid density functionals with long-range dispersion corrections: higher accuracy and extended applicability. Phys Chem Chem Phys 9:3397-3406. doi:10. 1039/B704725H

43. Head-Gordon M, Pople JA, Frisch MJ (1988) MP2 energy evaluation by direct methods. Chem Phys Lett 153:503-506. doi:10.1016/ 0009-2614(88)85250-3

44. Pople JA, Head-Gordon M, Raghavachari K (1987) Quadratic configuration interaction. A general technique for determining electron correlation energies. doi:10.1063/1.453520 
45. Dunning TH (1989) Gaussian basis sets for use in correlated molecular calculations. I. The atoms boron through neon and hydrogen. J Chem Phys 90:1007-1023. doi:10.1063/1.456153

46. Frisch MJ, Trucks GW, Schlegel HB, Scuseria GE, Robb MA, Cheeseman JR, Scalmani G, Barone V, Mennucci B, Petersson GA, Nakatsuji H, Caricato M, Li X, Hratchian HP, Izmaylov AF, Bloino J, Zheng G, Sonnenberg JL, Hada M, Ehara M, Toyota K, Fukuda R, Hasegawa J, Ishida M, Nakajima T, Honda Y, Kitao O, Nakai H, Vreven T, Montgomery JÁ Jr, Peralta JE, Ogliaro F, Bearpark M, Heyd JJ, Brothers E, Kudin KN, Staroverov VN, Kobayashi R, Normand J, Raghavachari K, Rendell A, Burant JC, Iyengar SS, Tomasi J, Cossi M, Rega N, Millam JM, Klene M, Knox JE, Cross JB, Bakken V, Adamo C, Jaramillo J, Gomperts R, Stratmann RE, Yazyev O, Austin AJ, Cammi R, Pomelli C, Ochterski JW, Martin RL, Morokuma K, Zakrzewski VG, Voth GA, Salvador P, Dannenberg JJ, Dapprich S, Daniels AD, Farkas Ö, Foresman JB, Ortiz JV, Cioslowski J, Fox DJ (2009) Gaussian Inc, Wallingford

47. Merrick JP, Moran D, Radom L (2007) An evaluation of harmonic vibrational frequency scale factors. J Phys Chem A 111:1168311700. doi:10.1021/jp073974n

48. McQuarrie DA, Simon JD (1999) Molecular Thermodynamic. University Science books, Sausalito, CA

49. Chase JMW (1998) NIST-JANAF thermochemical tables: fourth edn, Monograph 9 (part I and part II). NIST
50. Colin R, De Greef D (1975) The absorption Spectrum of the BeH and $\mathrm{BeD}$ molecules in the vacuum ultraviolet. Can J Phys 53:21422169. doi: $10.1139 / \mathrm{p} 75-262$

51. Peng C, Schlegel HB (1993) Combining synchronous transit and quasi-Newton methods for finding transition states. Israel J. Chem. 33:449-454

52. Atkins P, Paula J (2006) Physical chemistry, 8th edn. Oxford University Press

53. Todorov IT, Smith W, Trachenko K Dove MT (2006) J Mater Chem 16:1911-1918

54. Sukuba I (2015) A computational study of interactions in Be-W-D system relevant to fusion reactors. Disseration, Comenius University

55. Nishijima D, Doerner RP, Baldwin MJ, De Temmerman G, Hollmann EM (2008) Properties of BeD molecules in edge plasma relevant conditions. Plasma Phys Control Fusion 50:125007. doi: 10.1088/0741-3335/50/12/

56. Rackwitz, R.; Feldman, D.; Kaiser, H.J.; Heincke, E. (1977) Photodetachment bei einigen zweiatomigen negativen hydridionen: BeH-, MgH-, CaH-, ZnH-, PH-, AsH-. Z. Naturforsch 32a: 594.

57. Nielsen IMB, Janssen CL (1998) New diagnostics for coupledcluster and Møller-Plesset perturbation theory. Chem Phys Lett 290(4-6):423-430. doi:10.1016/S0009-2614(99)00770-8

58. Lee TJ, Taylor PR (1989) A diagnostic for determining the quality of single-reference electron correlation methods. Int J Quantum Chem 23:199-207 